\title{
MAPAS MENTAIS E EDUCAÇÃO AMBIENTAL: EXPERIÊNCIA COM ALUNOS DO ENSINO MÉDIO
}

\author{
Peter da Silva Rosa ${ }^{1}$ \\ Angelica Carvalho Di Maio²
}

Resumo: Diante do atual contexto que revela intensa degradação ambiental e reconhecendo a importância da educação para a transformação do status quo, o presente trabalho teve por objetivo analisar e compreender a percepção ambiental de estudantes do ensino médio em Itaboraí (RJ), por meio de mapas mentais. Além disso, foi desenvolvida a atividade de construção de representações geoespaciais dos problemas socioambientais do espaço de vivência do alunado, visando à prática de uma educação ambiental contextualizada. Apesar da importância de metodologias participativas como a supracitada, os resultados apontaram que a concepção mais abrangente e complexa de meio ambiente ainda foi muito limitada diante das visões tradicionais verificadas nas argumentações e nos produtos cartográficos.

Palavras-Chave: Mapas Mentais; Educação Ambiental; Percepção Ambiental.

Abstract: Given the current context that reveals intense environmental degradation and recognizing the importance of education for the transformation of the status quo, the present study aimed to analyze and understand the environmental perception of high school students in Itaboraí (RJ), through mind maps. In addition, the activity of building geospatial representations of socioenvironmental problems in the student's living space was developed, aiming at the practice of contextualized environmental education. Despite the importance of participatory methodologies such as the one mentioned above, the results showed that the most comprehensive and complex conception of the environment was still very limited in view of the traditional views verified in the arguments and cartographic product.

Key words: Mind Maps; Environmental Education; Environmental Perception.

${ }^{1}$ Universidade Federal Fluminense. E-mail: peterrosa@id.uff.br.

Link para o Lattes: http://lattes.cnpq.br/3581652944742709

2Universidade Federal Fluminense. E-mail: acdimaio@id.uff.br.

Link para o Lattes: http://lattes.cnpq.br/1971003943598869

Revbea, São Paulo, V. 15, № 1: 160-181, 2020. 


\section{Introdução}

A questão ambiental vem ganhando, desde da década de 1970, notoriedade nas discussões em diferentes aspectos da sociedade global, sobretudo em sua dimensão econômica. Segundo Leff (2010), o relatório intitulado "Os limites do crescimento" elaborado pelo Instituto de Tecnologia de Massachusetts (MIT, sigla em inglês) a pedido do Clube de Roma e publicado em 1972, colocou em evidência a crise ambiental como resultado de um processo de crescimento econômico desenfreado. Nesse sentido, "a consciência ecológica emerge como uma manifestação dos limites da economia" (LEFF, 2010, p.22). No entanto, apesar das diversas conferências realizadas ao longo das últimas décadas, da elaboração de inúmeros documentos e legislações, ainda convivemos com um quadro que revela intensa degradação do meio ambiente.

Ao longo desse tempo, nota-se, também, uma preocupação dos educadores em abordar a temática ambiental nos ambientes escolares, seja para cumprir com orientações pedagógicas institucionalizadas, seja por exclusivo reconhecimento da importância desta temática. Entretanto, verificase, ainda, que tal abordagem muitas vezes é desconexa da realidade de vivência do alunado, o que corrobora para a sua ineficácia.

Ao reconhecermos a escola como espaço profícuo para transformação do status quo, acreditamos que a partir dela poderemos construir caminhos os quais nos conduzam a novos horizontes, onde seja possível a amenização e/ou reversão do quadro de intensa degradação ambiental.

Concernente ao que foi exposto acima, faz-se necessário, a priori, um estudo da percepção ambiental no sentido de investigar e compreender os valores e as atitudes dos alunos em relação aos ambientes onde vivem. Nesse sentido, os mapas mentais são instrumentos auxiliadores nesse processo, pois constituem "uma forma de linguagem que expressa o espaço vivido representado em todas as suas nuances, cujos signos são construções sociais e os estudantes os agentes que as referendam" (KOZEL, 2008, p.86).

Sendo assim, o objetivo principal deste trabalho residiu em analisar e compreender a percepção do meio ambiente de alunos do ensino médio de uma escola pública localizada em Itaboraí - RJ, por meio de mapas mentais, além de ter proposto a construção de representações geoespaciais coletivas dos problemas socioambientais do município de vivência do alunado, visando à prática de uma educação ambiental contextualizada.

Acreditamos que a partir da análise da percepção ambiental por meio dos mapas mentais e a elaboração de atividades inseridas no contexto de uma metodologia participativa, como as representações geoespaciais, possamos caminhar no sentido de uma educação ambiental verdadeiramente alicerçada nos sujeitos e, por isso, capaz de gerar resultados mais satisfatórios. Dessa forma, almeja-se que essa experiência contribua para a construção de um processo de ensino e aprendizagem mais envolvente e significativo e, portanto, 
capaz de viabilizar a educação emancipatória e ações mais conscientes de intervenção socioambiental.

\section{Percepção e Educação Ambiental}

Conforme Hochberg (1973, p.11 apud MARIN, 2008, p. 206), "a percepção é um dos mais antigos temas de especulação e pesquisa no estudo do homem [...] Estudamos a percepção numa tentativa de explicar nossas observações do mundo que nos rodeia".

Contrapondo as perspectivas clássicas de abordagem da percepção, nas décadas de 20 e 30 do século passado, com a psicologia da Gestalt ou psicologia da forma, a "percepção deixa de estar relacionada a um inventário de associações sensoriais para tornar-se uma totalidade articulada onde o todo precede e condiciona a existência das partes" (CARVALHO e STEIL, 2013, p.61). Configura-se a partir daí um campo filosófico com influência da fenomenologia e do existencialismo. Esse novo enfoque será apreciado por várias áreas do conhecimento, dentre as quais encontra-se a geografia.

Com a consolidação da geografia humanista na década de 1970, a percepção ambiental sob a ótica da geografia ganhou grande destaque, sobretudo nas obras do geógrafo Yi-Fu Tuan. Esse autor nos diz que "percepção é tanto a resposta dos sentidos aos estímulos externos, como a atividade proposital, na qual certos fenômenos são claramente registrados, enquanto outros retrocedem para a sombra ou são bloqueados" TUAN (1980, p.4). Assim, nota-se que a percepção é uma atividade que envolve os sentidos e o ambiente, sendo composta pela "percepção sensorial" e pela "percepção cognitiva".

No que tange especificamente ao campo da Educação Ambiental, Helbel e Vestena (2017, p.69) destacam que "o estudo da Percepção Ambiental se relaciona a formas distintas de perceber ou sentir o espaço vivido, pois cada sujeito constrói seus valores ao se relacionar consigo mesmo e com o que o cerca". Essas autoras enfatizam que o tema da percepção ambiental é bastante relevante para a Educação Ambiental, pois favorece a reflexão sobre as problemáticas ambientais e a tomada de consciência do ambiente como construção dos sujeitos.

Ainda em relação a contribuição para a Educação Ambiental, Marin (2008) diz que os estudos sobre percepção não podem ficar limitados a visão das pessoas sobre os problemas ambientais, pois tal visão pode estar impregnada de informações midiáticas descontextualizadas. Ela defende que os estudos sobre percepção ambiental "[...] deveriam ir à gênese da existência e descrever os múltiplos modos de vida reveladores do real sentido de inserção do ser humano no seu ambiente [...]" (MARIN, 2008, p.216).

Apesar do consenso existente em torno da necessidade da Educação Ambiental para sociedade atual, há diferentes concepções e abordagens desse 
campo no que tange aos objetivos, ideais e práticas. A categorização dessas diversas concepções foi realizada por vários autores, dentre os quais destacam-se Layrargues e Lima (2011). Tais autores apresentam três macrotendências da Educação Ambiental: a conservadora, que se efetiva a partir das correntes conservacionista, comportamentalista, do autoconhecimento e da Alfabetização Ecológica; a pragmática, que está vinculada às correntes da Educação para o Desenvolvimento Sustentável e para o Consumo Sustentável; e a crítica, que abrange as correntes Popular, Transformadora, Emancipatória e no Processo de Gestão Ambiental.

Em consonância a essa diversidade de classificações, Carvalho (2001) também destaca que existe uma grande heterogeneidade de intencionalidades socioeducativas a respeito do ideário ambiental, sendo a Educação Ambiental um conceito que abarca ainda grande imprecisão e generalização. No entanto, afirma que "o foco de uma educação dentro do novo paradigma ambiental, portanto, tenderia a compreender, para além de um ecossistema natural, um espaço de relações socioambientais historicamente configurado e dinamicamente movido pelas tensões e conflitos socais" (CARVALHO, 2001, p.45). Nesse sentido, a autora define e defende a Educação Ambiental popular pelo seu caráter político e emancipatório.

Em sintonia com o que foi exposto, Sato (2001, p.20) destaca que a Educação Ambiental "clama pela liberdade de expressão, pela autonomia, pela diversidade e pela emancipação para a transformação de sociedades". A mesma autora chama a atenção para a valorização dos conhecimentos extra acadêmicos, próprios das comunidades e que muitas vezes são negligenciados.

\section{Mapas Mentais}

Dentre as várias definições sobre mapa mental encontradas na literatura, destaca-se a proposta por Kozel (2007, p.115) por ser uma das maiores referências na área, que nos diz que os mapas mentais são "uma forma de linguagem que reflete o espaço vivido representado em todas as suas nuances, cujos signos são construções sociais". Tal definição se aproxima das colocações sobre a construção do pensamento e da linguagem de Vigotski (2001), que destaca o signo como essencial constituinte da relação do sujeito com o mundo, revelando uma grande sintonia com Mikhail Bakhtin, autor privilegiado no embasamento dos trabalhos de Salete Kozel. Em consonância com essas considerações, Kozel (2007, p.132) fundamenta-se em Bakhtin ao afirmar que "as linguagens estão associadas ao homem/sociedade numa interação histórica, cultural e social, onde se estabelecem os discursos, que estão marcados pelo dialogismo, e os signos são produtos dessa construção social".

Segundo Seemann (2003), alguns fatores vão determinar os detalhes e os conteúdos dos mapas mentais, tais como capacidade, habilidade e escala de percepção dos seus autores. No entanto, ao trabalhar com mapas mentais

revista brasileira educação ambiental 
não se deve intervir no processo de produção no sentido de propor algum parâmetro. Assim, "ao estudar os mundos mentais das pessoas, não podemos impor categorias acadêmicas e artísticas, mas devemos interpretar os mapas como uma fonte de comunicação" (SEEMANN, 2003, p.15). Nesse sentido, Kozel (2008) destaca a importância desses mapas para a prática pedagógica, por proporcionarem aos alunos a interlocução como atores sociais e construtores do espaço geográfico.

Quanto à questão específica da percepção ambiental, a importância dos mapas mentais é demonstrada através do seguinte fragmento:

Com o uso dos mapas mentais, para a representação da realidade ambiental, cada signo (as "palavras" do mapa) poderá servir de referência para um elemento que conduz ao entendimento da percepção ambiental dos estudantes. Os mapas mentais possibilitam a inclusão de elementos subjetivos que, geralmente, não estão presentes nos mapas tradicionais e remetem aos sentimentos topofílicos e topofóbicos, fazendo com que o mapeador expresse sua afetividade e, muitas vezes, seu inconsciente. (BATISTA, BECKER e CASSOL, 2015, p. 3408).

Portanto, a construção de mapas mentais possibilita o desvendamento de uma realidade sob ótica dos sujeitos que vivenciam o seu espaço. Dessa forma, a sua utilização é recomendada para se tentar compreender a percepção do meio ambiente dos alunos como forma de construção de uma educação mais contextualizada e compromissada com a sociedade.

\section{Metodologia}

Esta pesquisa teve como enfoque metodológico a fenomenologia que se preocupa com o estudo das essências, constituindo um dos caminhos favoráveis a investigação da percepção do meio ambiente. Trata-se de uma abordagem qualitativa que é muito importante nos estudos relacionados à educação, como é o foco deste trabalho.

Com o intuito de compreender a percepção do meio ambiente dos espaços de vivência de alunos do ensino médio, utilizamos os mapas mentais como forma de linguagem e a "metodologia Kozel" para a decodificação e interpretação de tais mapas. Esta metodologia foi construída a partir da Teoria Enunciativa da Linguagem de Mikhail Bakhtin (KOZEL, 2007).

Nesse contexto, para analisar os conteúdos dos mapas mentais, seguimos a proposta de Kozel (2007), que perpassa pelos seguintes quesitos: 
1. Interpretação quanto à forma de representação dos elementos na imagem: ícones diversos, linhas, letras, mapas, figuras geométricas, dentre outras.

2. Interpretação quanto à distribuição dos elementos na imagem: dispostas horizontalmente, de forma dispersa, isolada, em quadros, em perspectiva, etc.

3. Interpretação quanto à especificidade dos ícones: a autora definiu quatro categorias (representação dos elementos da paisagem natural, os da paisagem construída, os elementos móveis e os humanos).

4. Apresentação de outros aspectos ou particularidades: nesse quesito, a autora exemplifica através de contrastes urbanos e problemas sociais como a prostituição e marginalização. No entanto, no nosso caso, esteve relacionado às particularidades do contexto de vivência dos alunos no município de Itaboraí.

Após as investigações da percepção do meio ambiente através dos mapas mentais, foi proposta a elaboração de representações geoespaciais coletivas dos problemas socioambientais dos espaços de vivência dos alunos. Trata-se de uma atividade didático-pedagógica que buscou integrar e envolver os estudantes na construção de um conhecimento e objetivou contribuir para o processo de Educação Ambiental.

Inseridas no contexto de uma metodologia participativa, as representações geoespaciais coletivas realizadas pelos alunos podem viabilizar reformulações pedagógicas essenciais para a transformação da nossa realidade educacional "tradicional" e conduzir a mudanças socioambientais tão urgentes para o bem-estar da sociedade. Nesse sentido, "as metodologias participativas aplicadas ao contexto educativo visam a contribuir com a transformação social e com a construção de práxis pedagógicas inovadoras" (BACCI, SANTOS e MARTINS, 2017, p.7).

Segundo Bacci e Santos (2013, p. 20), o mapeamento socioambiental "possibilita o re(conhecimento) do local e seus problemas, bem como o compartilhamento de informações, vivências e percepções sobre a realidade socioambiental'. Percebe-se, através dessa colocação, a aproximação com as considerações da primeira parte do trajeto da pesquisa que envolvia a percepção do meio ambiente do espaço de vivência do alunado. Apesar de não se tratar propriamente de um mapeamento, as representações geoespaciais coletivas dos problemas socioambientais produzidas em meio digital se assemelham às intencionalidades destacadas por Bacci e Santos (2013) pois viabilizam também o re(conhecimento) espacial de tais problemas e a partilha de informações e percepções sobre o espaço de vivência.

Sendo assim, foi desenvolvida a segunda parte do trabalho com base em Bacci e Santos (2013), que propuseram uma metodologia específica para o mapeamento socioambiental, estando atrelada às seguintes etapas: $1^{\text {a }}$ elaboração do mapa mental realizado antes da saída de campo; $2^{\mathrm{a}}$ -

revista brasileira educação ambiental 
elaboração do mapa socioambiental local objetivando o levantamento em campo de dados dos aspectos socioambientais (neste momento foi solicitado que os alunos fotografassem e elaborassem vídeos sobre os problemas socioambientais); $3^{\underline{a}}$ - elaboração do mapa síntese; $4^{\underline{a}}$ - elaboração do mapa propositivo. No entanto, para trabalho em tela, considerou-se tal metodologia com algumas adaptações. A preocupação no desenvolvimento dessa atividade, para atingir o objetivo proposto, focalizou os problemas socioambientais. Além disso, a quarta etapa foi adaptada como forma de discussões e debates na apresentação do trabalho para a comunidade escolar.

Para confecção das representações geoespaciais, utilizou-se o "Guia para realização da Etapa II - Fase 3" da II Olimpíada Brasileira de Cartografia (OBRAC), que orientou os grupos participantes da referida olimpíada na construção de representações digitais a partir do Google My Maps, "uma ferramenta da empresa Google, que possibilita a 'criação' de mapas personalizados a partir do Google Maps" (OBRAC, 2017, n.p.).

Para desenvolvimento da pesquisa foram considerados os alunos de quatro turmas do $2^{\circ}$ ano do Ensino Médio regular de uma escola pública localizada em Itaboraí - RJ, totalizando 110 estudantes.

\section{Resultados e discussão}

Os resultados da pesquisa são oriundos da decodificação e interpretação dos mapas mentais sobre o meio ambiente, elaborados pelos alunos das quatro turmas do segundo ano do ensino médio, identificadas por nomes fictícios do alfabeto grego: Alfa, Beta, Gama e Delta; das observações e análises do processo de construção das representações geoespaciais coletivas dos problemas socioambientais; e por fim, da observação da apresentação do trabalho para a comunidade escolar.

\section{Decodificação e interpretação dos mapas mentais}

A decodificação e análise dos mapas mentais foi realizada a partir da "metodologia Kozel" (KOZEL, 2007). A primeira categoria de análise apresentada por essa metodologia compreende a interpretação quanto à forma de representação dos elementos na imagem: ícones diversos, linhas, letras, mapas, figuras geométricas, dentre outras. Nota-se, a partir da Tabela 1, que os ícones constituem a forma de representação mais utilizada, assim como no trabalho de Marques (2012), chegando a estar presente na totalidade das representações, exceto das turmas Beta e Delta. 
Tabela 1: Formas de representação dos elementos no mapa mental sobre o meio ambiente do espaço de vivência por turma pesquisada.

\begin{tabular}{lcccc}
\hline \multicolumn{1}{c}{$\begin{array}{c}\text { Formas de } \\
\text { representação }\end{array}$} & Alfa & Beta & Gama & Delta \\
\cline { 2 - 5 } & 38 & 33 & 18 & 16 \\
\hline Ícones diversos & 23 & 25 & 14 & 08 \\
\hline Letras & 01 & 05 & 01 & 00 \\
\hline Mapas & 07 & 01 & 01 & 02 \\
\hline Figuras geométricas & &
\end{tabular}

Total de alunos que realizaram a tarefa - Turma Alfa $=38$; Turma Beta $=36$; Turma Gama $=$ 18; Turma Delta $=18$. Fonte: Dados da pesquisa.

As letras foram a segunda forma mais frequente nas representações. Essa forma esteve presente em $60,53 \%$ das representações da turma Alfa, em $69,44 \%$ da turma Beta, em $77,78 \%$ da turma Gama e em $44,44 \%$ da turma Delta, como pode ser verificado na Tabela 1.

A presença das letras indicava, na maioria dos casos analisados, elementos que os estudantes queriam evidenciar ou pontos de referência significativos do seu espaço de vivência, que eram escritos sobre a própria imagem o seu significado, tais como "minha casa", "minha rua", "mercado" etc. Nesse sentido, Marques (2012, p.62) ratifica essa ideia através da seguinte colocação: "a presença das letras evidencia o que o aluno quer destacar em seu mapa mental. Isso aumenta a ideia de representação e início de legenda".

Em outros casos, as letras estavam associadas a ícones não muito bem definidos/elaborados, que o autor julgava que os leitores não fossem compreender. Há ainda situações onde as letras formavam frases de efeito para descrever uma dada situação presente no seu cotidiano ou algo que ele almejava, como por exemplo, "Paz na favela" (aluno da turma Beta).

Quanto à presença de mapa, que constitui uma "representação espacial dando forma e contorno ao lugar" (KOZEL, 2001 apud MARQUES, 2012, p.62), verificou-se a sua utilização em 7 representações, o que corresponde a $6,36 \%$ do total dos mapas mentais elaborados, como pode ser observado na Tabela 1.

Outra forma encontrada em 11 mapas mentais foi a figura geométrica, que corresponde a $10 \%$ do total das representações, como se pode notar na Tabela 1.

Um exemplo de um mapa mental com diferentes formas de representação é apresentado na Figura 1. Ele evidencia a representação espacial de Itaboraí por meio de um mapa, mesmo que muito distante do formato original do município representado pelos mapas oficiais. Isso revela que 0 aluno desconhece minimamente a cartografia do seu município. Percebe-se, no mapa em questão, uma regionalização baseada em características relativas a diferentes usos do espaço e aspectos socioeconômicos. 
Além do mapa, observa-se também diferentes ícones bem definidos, mesmo assim, tiveram identificação reforçada pelas palavras escritas em placas e em duas lixeiras.

Através das regiões destacadas pelo aluno, nota-se que houve o predomínio de aspectos negativos relacionados ao meio ambiente, que perpassam por uma degradação social, econômica e ecológica. As únicas exceções são a região em amarelo com a placa "lugar melhor" e a região onde consta uma construção e um carro em um lugar composto por uma área verde e colinas ao fundo. Verifica-se, então, um contraste socioambiental materializado através da composição dos ícones depreciativos das demais regiões que apresentam drogas, assalto/arma de fogo, resíduos sólidos depositados indevidamente sobre o solo, "empresa falida" e propriedade à venda.

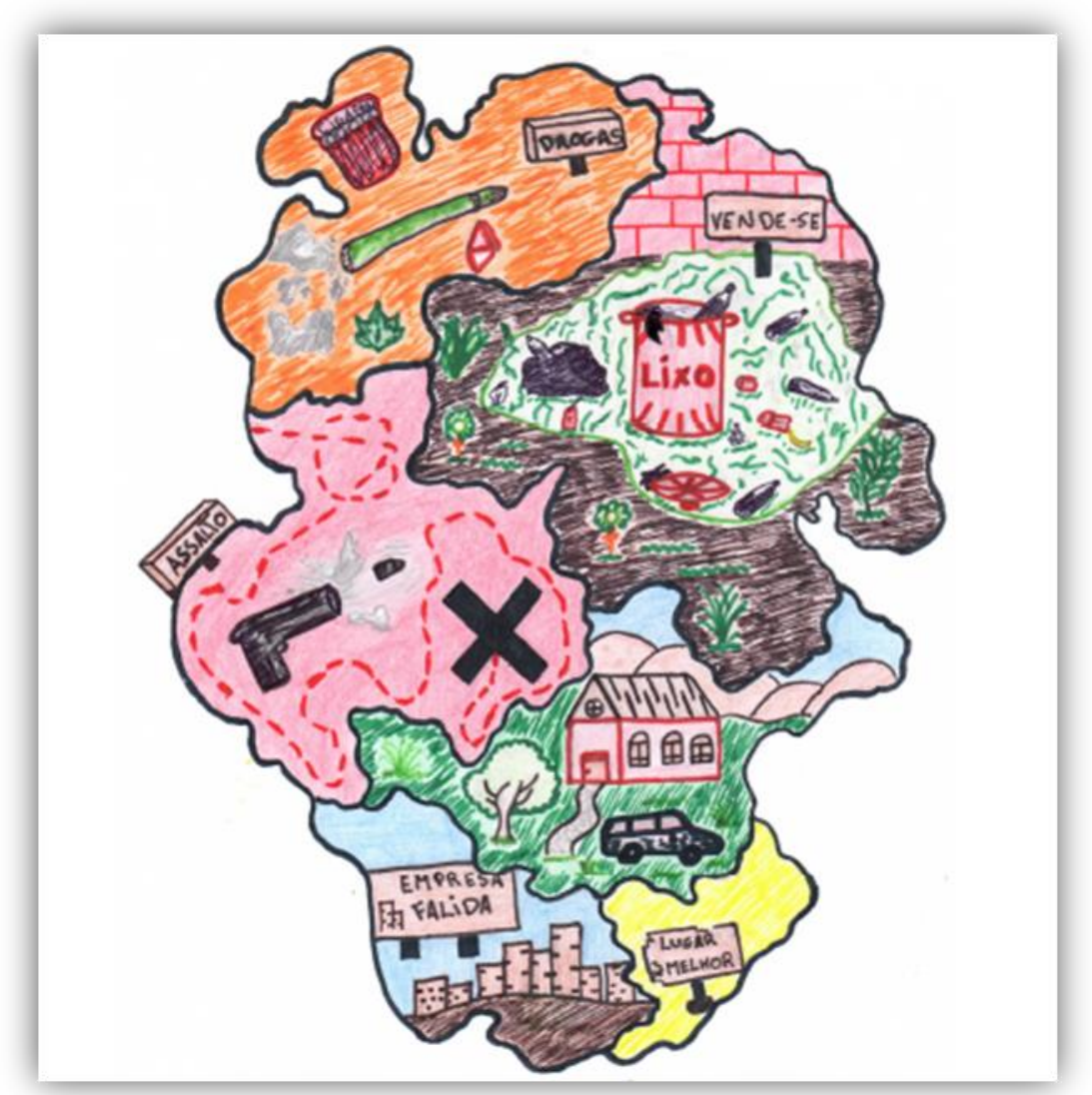

Figura 1: Mapa mental do aluno ATG09 sobre o meio ambiente do espaço de vivência.

Fonte: Dados da Pesquisa 
Rio Janeiro. Um fato agravante para a crise no contexto municipal foi a paralisação do Complexo Petroquímico do Rio de Janeiro (Comperj), gerando a falência de muitas empresas, fenômeno também representado pelo aluno e ratificado nas palavras de Branco et al. (2016, p.2) referente a esse contexto: "a economia local foi severamente impactada e os desdobramentos percebidos se associam diretamente a elevação da taxa de mortalidade de micro e pequenas empresas".

No tocante à distribuição dos elementos na imagem, foram encontradas as seguintes formas nos mapas mentais: horizontal, vertical, perspectiva, dispersa, em quadros, em áreas, oblíqua e a combinação horizontal e vertical, como pode ser observado na Tabela 2.

Tabela 2: Distribuição dos elementos no mapa mental sobre o meio ambiente do espaço de vivência por turma pesquisada

\begin{tabular}{lcccc}
\multirow{2}{*}{ Tipos de distribuição } & Alfa & Número de alunos & Gama & Delta \\
\cline { 2 - 5 } & 15 & 14 & 12 & 10 \\
\hline Horizontal & 3 & 7 & 1 & 2 \\
\hline Vertical & 1 & 2 & 1 & - \\
\hline Perspectiva & 1 & 1 & - & 1 \\
\hline Dispersa & - & 1 & - & 1 \\
\hline Em quadros & - & 4 & 1 & - \\
\hline Em áreas & 2 & - & 1 & 3 \\
\hline Oblíqua & 16 & 7 & 2 & \\
\hline Horizontal e vertical & & & &
\end{tabular}

Total de alunos que realizaram a tarefa - Turma Alfa $=38$; Turma Beta $=36$; Turma Gama $=$ 18; Turma Delta $=18$. Fonte: Dados da pesquisa.

A forma predominante de distribuição dos elementos nos mapas foi a horizontal, exceto na turma Alfa, onde a combinação horizontal e vertical foi a mais expressiva. O predomínio dessa visão horizontal demonstra que 0 estudante buscou representar como ele vê quando está na posição de pé. A combinação horizontal e vertical foi a segunda mais utilizada, o que atesta o embaraço em coordenar ponto de vista. De acordo com Passini (1988 apud SOUZA; PEREIRA, 2017, p.265), "essa é uma característica da fase egocêntrica entre as crianças, apresentada como uma incapacidade". Porém, quanto aos adultos, essa dificuldade em coordenar ponto de vista não está associada a "incapacidade cognitiva, mas possivelmente a falta de conhecimento e aplicação da técnica da vista aérea" (SOUZA; PEREIRA, 2017, p.265).

O mapa mental presente na Figura 2 constitui um exemplo de representação com distribuição dos elementos na forma horizontal. $\mathrm{Na}$ composição da imagem existe um acúmulo de lixo que atrai urubus a partir do odor. É interessante observar que para representar o mal cheiro proveniente dos resíduos sólidos, o aluno utilizou três linhas tracejadas. De acordo com Sousa (2012, p.189), "[...] o odor é capaz de orientar se determinado lugar é ou não agradável, pois lugares com odores desagradáveis tornam-se repudiados e 
provocam sentimentos negativos no ser humano". Nesse sentido, na representação em tela, o odor desagradável resultante do lixo é um dos elementos que compõem os problemas do lugar. Observa-se ainda que o sol é representado de forma lúdica e esboça um semblante de tristeza diante de um ambiente marcado pela degradação socioambiental.

Nota-se também na Figura 2 a presença de um prédio abandonado, que traduz o contexto socioeconômico atual do município de Itaboraí. Com a paralisação das obras do Comperj devido à crise instaurada nos últimos anos, muitos imóveis criados por uma especulação imobiliária estão abandonados ou subutilizados, o que segundo Duba (2016, p.94 e 95), "demonstra a incapacidade de absorção pelo mercado. Eles custaram caro e foram construídos a partir de uma estética moderna que não condiz com a realidade de Itaboraí, por isso não tem quem alugue e quem pague por eles".

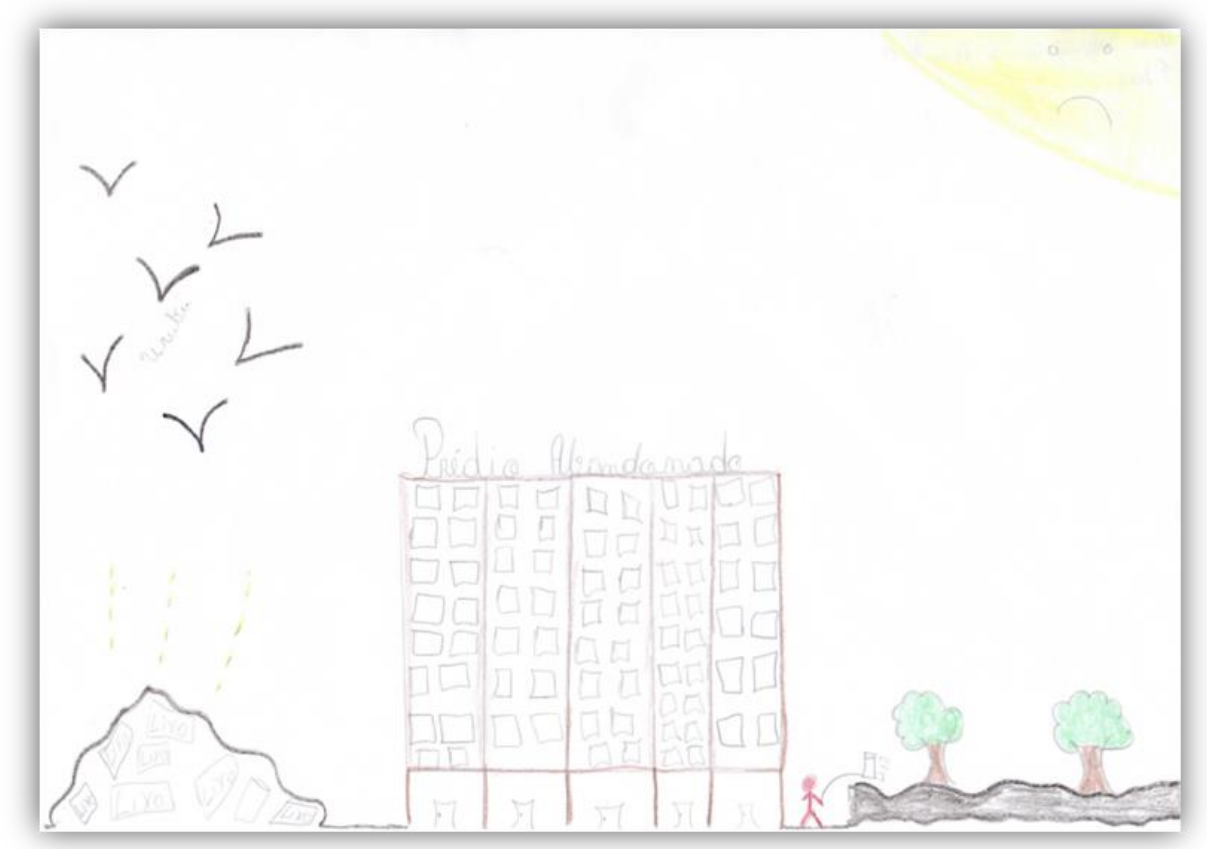

Figura 2: Mapa mental do aluno ATD06. Fonte: Dados da Pesquisa

O terceiro passo da "metodologia Kozel" visa a interpretação das especificidades dos ícones que compõem os mapas mentais, tais como a representação dos elementos da paisagem natural, os da paisagem construída, os elementos móveis e os humanos. "A interpretação quanto à especificação dos ícones requer uma análise mais detalhada, pois evidencia aspectos mais complexos. Nota-se que se trata de um universo permeado pelo simbólico em que perpassam vários elementos para a composição das imagens" (KOZEL e GALVÃO, 2008, p.41).

A Tabela 3 exibe os resultados encontrados nos mapas mentais dos estudantes em relação às especificidades dos ícones, que traduzem elementos que constituem o espaço de vivência, sendo, portanto, fundamentais na análise 
dos mapas mentais. Segundo Marques (2012, p.66), "esses elementos dão vida a um lugar, pois se pode entendê-lo como humanizado, isto é, com interferência humana e traços culturais do povo". No entanto, foi percebido através da análise dos mapas mentais, que apesar da quase totalidade dos alunos destacarem elementos da paisagem construída (produto do trabalho humano), a inserção dele ou de outras pessoas diretamente na representação foi muito limitada, resultado semelhante ao apresentado por Marques (2012). Kashiwagi (2004, p.144) destaca que esse contraponto é importante para "detectarmos a percepção que esses indivíduos [...] têm a respeito do meio ambiente e como isso reflete cultural e socialmente no espaço, [...] uma vez que se prioriza o ambiente construído e não se considera o homem como sujeito".

Tabela 3: Especificidades dos ícones encontrados no mapa mental sobre o meio ambiente do espaço de vivência por turma pesquisada

\begin{tabular}{lcccc}
\hline \multicolumn{1}{c}{ Tipos de especificidades } & Alfa & Búmero de alunos & Gama & Delta \\
\cline { 2 - 5 } & 32 & 29 & 16 & 17 \\
\hline Elementos da paisagem natural & 38 & 31 & 18 & 17 \\
\hline Elementos da paisagem construída & 09 & 08 & 04 & 05 \\
\hline Elementos móveis & 05 & 06 & 02 & 03 \\
\hline Elementos humanos
\end{tabular}

Total de alunos que realizaram a tarefa - Turma Alfa $=38$; Turma Beta $=36$; Turma Gama $=$ 18; Turma Delta $=18$. Fonte: Dados da pesquisa.

Verificou-se que apenas $16,67 \%$ dos alunos das turmas Beta e Delta representaram elementos humanos nos mapas mentais sobre o meio ambiente. Em relação a esse mesmo tipo de atividade, as turmas Alfa e Gama apresentaram resultado ainda mais inferior, onde somente $13,16 \%$ e $11,11 \%$ dos estudantes, respectivamente, inseriram elementos humanos em seus mapas mentais, conforme Tabela 3.

Na representação de um aluno da turma Delta, constante na Figura 3, nota-se a presença de elementos humanos na fila do hospital, na motocicleta e envolvidos na supressão da vegetação. Eles compõem cenas que representam problemas socioambientais, como a questão das dificuldades na área da saúde, a violência urbana (retratada pela perseguição policial) e o desmatamento. Em apenas uma cena não se verifica a presença do elemento humano, mas expressa também um problema que é a emissão de poluentes na atmosfera por uma cerâmica, atividade econômica tradicional em Itaboraí.

Os elementos móveis foram amplamente representados através do grande número de veículos, como se pode visualizar na Figura 3, imprimindo a ideia de movimento na composição, o que caracteriza o espaço como dinâmico. Observa-se que o aluno deu ênfase a poluição gerada pelos carros, representando a fumaça lançada por eles.

Portanto, nota-se, mais uma vez, que apesar de se tratar do mapa do meio ambiente e não especificamente dos problemas socioambientais, tais problemas dominaram a percepção do aluno em relação ao meio ambiente do 
seu espaço de vivência. Dessa forma, percebe-se uma tendência no destaque de elementos depreciativos relacionados ao mesmo contexto social e histórico, o que reflete a interação entre os sujeitos. Nesse sentido, "a codificação dos signos que formam a imagem não é apenas uma representação individual, mas coletiva, na medida em que compartilha valores e significados com comunidades e redes de relações, referendando um signo social' (KOZEL, 2007, p.132).

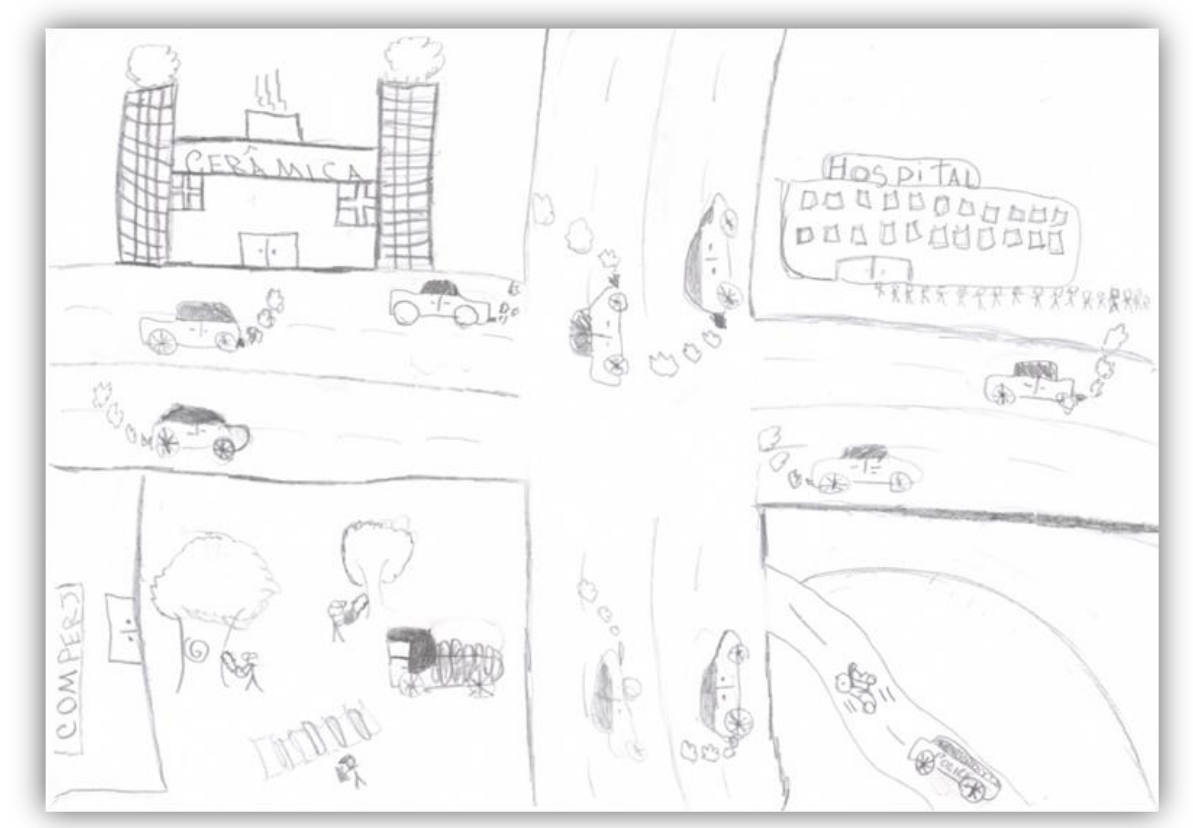

Figura 3: Mapa mental do aluno ATD12. Fonte: Dados da Pesquisa

Por fim, a quarta fase de análise da "metodologia Kozel" consiste na apresentação de outros aspectos ou particularidades que, no nosso caso, estiveram associados ao contexto de vivência dos alunos que abrange predominantemente $01^{\circ}$ distrito (sede) do município de Itaboraí. Quanto a essa fase, Kozel (2007, p.135) destaca que "a observação e seleção dos mapas realizadas nas fases anteriores permitirá que se estabeleça a codificação das mensagens [...]".

Por meio da análise dos mapas mentais elaborados pelos alunos detectou-se que os dois aspectos mais frequentes foram a representação dos resíduos sólidos (lixos) depositados inadequadamente no ambiente (em terrenos baldios, ruas ou lagos) e a representação da má conservação das avenidas ou ruas, com destaque para os buracos, como pode ser visualizado na Tabela 4.

É relevante destacar que mesmo o comando para a elaboração do mapa apenas solicitar a representação sobre o meio ambiente do espaço de vivência, sem especificar a dimensão dos problemas, grande parte do alunado enfatizou os problemas socioambientais. Tal abordagem é condizente com o 
contexto atual de Itaboraí, como destaca Moniz (2016, p.38), "o município enfrenta sérios problemas socioambientais e estruturais, incluindo a ausência de infraestrutura urbana, de saneamento básico e carência de serviços públicos de saúde e educação". Portanto, nota-se que a percepção ambiental do espaço de vivência dos estudantes está fortemente associada aos problemas socioambientais, ou seja, aquilo que interfere de forma negativa no seu cotidiano, contribuindo para uma visão depreciativa do seu lugar. Nesse sentido, Duba (2016, p.138 e 139) acrescenta as consequências negativas do Comperj para a cidade, dizendo que a passagem de tal empreendimento "deixou um rastro de destruição, através da concentração de renda, das desigualdades, do encarecimento do valor dos imóveis, da existência de uma suposta crise, do sucateamento da saúde e da educação, da degradação ambiental e da vida". Essas constatações degradantes permeiam os discursos sociais e se refletiram intensamente nos mapas mentais elaborados pelos estudantes.

Tabela 4: Outros aspectos ou particularidades encontradas nos mapas mentais sobre o meio ambiente do espaço de vivência por turma pesquisada.

Descrição dos aspectos ou particularidades Número de alunos

\begin{tabular}{|c|c|c|c|c|}
\hline \multirow[t]{2}{*}{ Descrição dos aspectos ou particularidades } & \multicolumn{4}{|c|}{ Número de alunos } \\
\hline & Alfa & Beta & Gama & Delta \\
\hline $\begin{array}{llll}\text { Resíduos } & \text { sólidos } & \text { (lixo) } & \text { depositados }\end{array}$ & & & & \\
\hline $\begin{array}{l}\text { inadequadamente no ambiente (terrenos baldios, ruas } \\
\text { ou lagos) }\end{array}$ & 10 & 5 & 6 & 4 \\
\hline $\begin{array}{l}\text { Ruas, avenidas ou calçadas } \\
\text { (pavimentadas ou sem pavimentação) }\end{array}$ & 11 & 12 & 4 & 9 \\
\hline Poluição de córregos por esgoto ou resíduos sólidos & 4 & 5 & - & 3 \\
\hline Esgoto a céu aberto & 5 & - & - & 2 \\
\hline $\begin{array}{l}\text { Queima de resíduos sólidos (lixo) e poluição do ar } \\
\text { decorrente dessa ação }\end{array}$ & 1 & 1 & 5 & - \\
\hline Poluição do ar provocada por atividade industrial & 1 & - & - & 2 \\
\hline Pichação & - & 1 & - & - \\
\hline Número grande de veículos nas ruas & 1 & - & - & 1 \\
\hline Poluição do ar por veículos & - & - & - & 2 \\
\hline Desmatamento & - & 2 & - & 1 \\
\hline Poluição (tipo não identificado) & - & 2 & - & 1 \\
\hline Violência urbana (tiroteio e assalto) & - & - & 3 & 1 \\
\hline Drogas ilícitas e tráfico & - & - & 1 & 1 \\
\hline "Cemitério clandestino" & - & - & 1 & - \\
\hline Empresa falida & - & - & 1 & - \\
\hline $\begin{array}{l}\text { Propriedade à venda ou abandonada (casa, prédio ou } \\
\text { terreno) }\end{array}$ & - & - & 1 & 1 \\
\hline Contraste social & - & - & 1 & - \\
\hline Fila em Hospital & - & - & - & 1 \\
\hline Fio da rede elétrica arrebentado & - & - & - & 1 \\
\hline
\end{tabular}

Total de alunos que realizaram a tarefa - Turma Alfa $=38$; Turma Beta $=36$; Turma Gama $=$ 18; Turma Delta $=18$. Fonte: Dados da pesquisa. 


\section{Análise das representações geoespaciais coletivas dos problemas socioambientais}

As representações geoespaciais coletivas dos problemas socioambientais do espaço de vivência foram concebidas com o intuito de contribuir para uma prática pedagógica mais criativa, dinâmica e contextualizada, favorecendo, assim, o processo de aprendizagem mais significativo e eficaz. Trata-se de uma atividade que buscou motivar o estudante a exercer seu papel de cidadão no engajamento e transformação da realidade socioambiental que faz parte do seu espaço cotidiano. Essa consideração está de acordo com o que nos diz Bacci e Santos (2013, p.22), "[...] para que o indivíduo exerça de fato a cidadania, o conhecimento sobre $o$ ambiente em que vive é necessário para interpretar, julgar e atuar na sociedade de forma responsável [...]".

Foram realizadas quatro representações geoespaciais em momentos distintos, uma de cada turma (Alfa, Beta, Gama e Delta). No início de cada elaboração, foi apresentado o Guia da II OBRAC e depois os alunos começaram a discutir sobre os problemas socioambientais verificados em seus bairros. Em seguida, eles inseriram o título no mapa e na descrição formularam objetivos da atividade conforme as discussões realizadas. Posteriormente, os grupos foram inserindo os pontos e as fotos dos problemas detectados em seus espaços de vivência.

Cada turma elaborou sua própria descrição com os objetivos da atividade e os ícones representativos dos problemas também foram escolhas próprias, assim como as legendas das imagens. A Figura 4 apresenta uma imagem do trabalho realizado pela turma Gama, onde se visualiza em destaque o "Ponto 6 - Esgoto a céu aberto" e a legenda bastante objetiva da foto, que diz: "Esgoto a céu aberto evidenciando a falta de saneamento básico". No canto esquerdo da imagem verifica-se a lista parcial dos pontos inseridos pelos alunos, envolvendo, predominantemente, problemas associados aos resíduos sólidos, efluentes domésticos (esgoto) e ruas mal conservadas. Tais problemas também constituíram uma tendência nos produtos cartográficos das demais turmas analisadas.

Quanto aos objetivos elencados pelas turmas e transcritos nas representações, percebe-se que esboçam uma síntese das discussões realizadas entre eles e mediadas pelo professor pesquisador. Tratam de objetivos que buscam desvendar para a sociedade a realidade socioambiental do município de Itaboraí, além de exigirem a solução de tais problemas, como nos seguintes exemplos: "Apontar os problemas socioambientais em Itaboraí; Chamar a atenção da população para os problemas socioambientais; Exigir dos órgãos competentes a solução dos problemas socioambientais visando a uma melhor qualidade de vida para a população". São objetivos bastante pertinentes, porém, despidos de autocrítica e de uma análise política e econômica mais engajada. Não foi constatado um questionamento do sistema 
vigente e nem as artimanhas engendradas pelo seu inerente padrão mercadológico e consumista.

No entanto, apesar da falta de aprofundamento das questões políticas e de uma visão mais abrangente por parte do alunado, foram notadas algumas "pinceladas" de uma percepção mais holística como a verificada no Ponto 3 da representação geoespacial da turma Delta, que apresenta, em destaque, uma obra abandonada do PAC em Itambí com a seguinte legenda: "Obra abandonada do PAC em Itambí. Demonstração de irresponsabilidade com o dinheiro público e com a população que não tem moradia própria”. Constata-se, nesse exemplo, uma abordagem que foge ao padrão conservador ligado exclusivamente a dimensão ecológica e naturalista de meio ambiente. Trata-se da colocação de uma problemática ancorada em uma complexidade que abrange múltiplas dimensões (social, política, econômica e ambiental) e que foi sabidamente percebida pelo aluno que a identificou como um problema socioambiental.

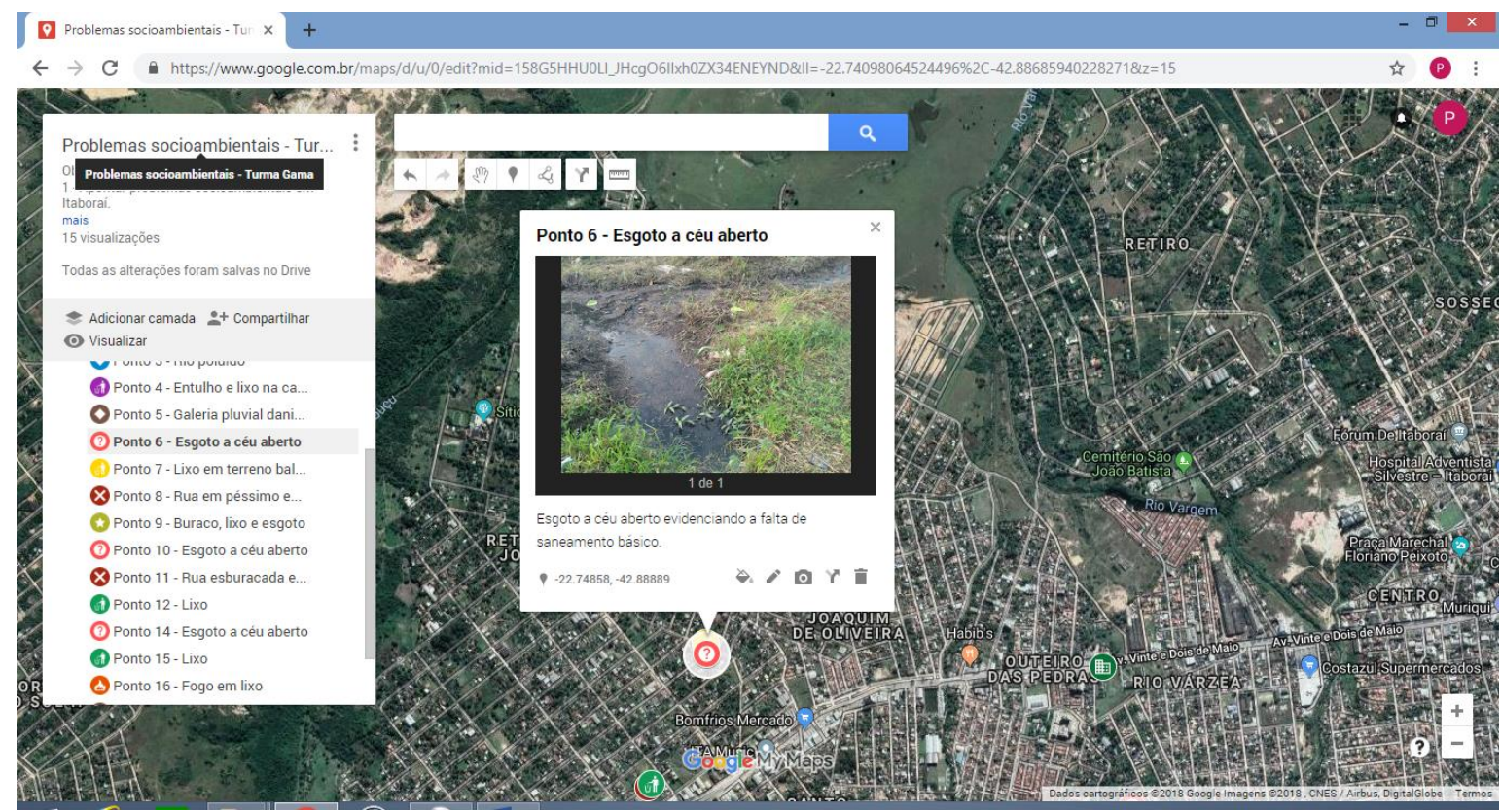

Figura 4: Imagem da representação geoespacial coletiva digital da Turma Gama com destaque para o Ponto 6 - Esgoto a céu aberto. Fonte: Dados da Pesquisa

Verificou-se, através da análise da percepção dos estudantes, que tal atividade contribui significativamente para o processo de educação ambiental, envolvendo a participação coletiva e mobilização em relação aos problemas socioambientais verificados em seu contexto de vivência. Pelo fato de ter enfocado realidades locais, o trabalho foi dotado de um caráter mais significativo e consequentemente mais eficaz no processo de desenvolvimento de construção de uma educação ambiental crítica, mais preocupada com a transformação da sociedade. No entanto, apesar desses pontos positivos, os 
mapas privilegiaram aspectos associados à falta de pavimentação, aos resíduos sólidos e aos efluentes domésticos, sem uma repercussão mais sólida sobre a estrutura social, política e econômica que envolve o sistema hegemônico. Percebeu-se que mesmo diante das discussões travadas sobre os problemas socioambientais que perpassam pelas dimensões socioeconômicas e políticas, a concepção mais abrangente e complexa de meio ambiente ficou comprometida pela predominante despolitização verificada nos produtos cartográficos.

Essa dificuldade demonstrada pelos alunos em relação à problematização política mais consistente está atrelada a um contexto ainda amplamente tradicional e acrítico. Apesar dessa limitação diagnosticada, a atividade realizada serviu como início de uma prática pedagógica mais contextualizada, constituindo um dos pilares da educação ambiental crítica, fundamental para o comprometimento com a transformação da realidade socioambiental. Nesse sentido, nos apropriamos das seguintes palavras:

[...] A ruptura com os paradigmas vigentes não será feita de maneira instantânea ou em curto prazo e, assim, inserir novas perspectivas na sociedade e escola, esta como parte fundamental da reprodução e contestação do sistema contemporâneo, será um trabalho árduo que deverá criticamente ser desenvolvido de forma coletiva e com práticas criativas, em compreensão de que meio ambiente e sociedade estão intimamente interligados. E contextualizar temporal e espacialmente as temáticas ambientais é, desde já, uma tarefa necessária para desenvolver uma educação ambiental mais crítica (CRUZ; TEODORO, 2016, p.45 e 46).

Uma sinalização de que estamos no caminho correto foi o fato de que, no decorrer da atividade desenvolvida, diversos alunos demonstraram interesse em divulgar os resultados do trabalho para a comunidade escolar e autoridades do município de Itaboraí, postura atípica diante da resistência habitual com as apresentações orais. Essa atitude está em consonância com o que afirma Bacci e Santos $(2013$, p.20) ao relatarem que os dados espacializados em representações socioambientais podem contribuir para mobilizar as pessoas envolvidas numa "[...] apreensão crítica do meio focalizado, implicando na superação de posturas muitas vezes passivas frente aos problemas socioambientais locais".

\section{Apresentação e debate sobre os problemas socioambientais}

A apresentação consistiu na demonstração das representações geoespaciais e vídeos, produzidos coletivamente, sobre os problemas socioambientais. Após a exposição desses materiais ocorreu um debate cujo principal objetivo era fomentar o levantamento de propostas para a amenização e/ou solução dos problemas socioambientais do espaço de vivência. Neste 
debate, além dos alunos estabelecerem ações, ainda definiram as responsabilidades para viabilizar as transformações necessárias para uma melhor condição do ambiente onde vivem.

A partir das observações e análises dessa atividade, notou-se, mais uma vez, que as percepções sobre o meio ambiente e sobre os problemas socioambientais são limitadas, na maior parte, aos aspectos relacionados aos resíduos sólidos, efluentes domésticos e falta de pavimentação das ruas. $O$ trecho de um dos vídeos produzidos por um grupo da turma Alfa ilustra essa constatação: "Nesse vídeo podemos claramente ver diversos problemas socioambientais como: esgoto a céu aberto, muitos entulhos, lixos na rua, rua cheia de buracos sem asfalto, e tudo isso afeta de maneira direta os moradores, podendo levar doenças e o mal deslocamento devido a falta de asfalto e buracos de sobra...".

Quanto às propostas levantadas pelos alunos para solucionar os problemas socioambientais, verificou-se que também estão predominantemente associadas aos resíduos sólidos, aos efluentes domésticos e à pavimentação das ruas, conforme demonstrado no Quadro 1.

Quadro 1: Propostas e responsabilidades definidas pelos alunos para a solução dos problemas socioambientais.

\begin{tabular}{|c|c|}
\hline Propostas & Responsabilidades \\
\hline Implementar a coleta regular de lixo nos locais onde não possui & Prefeitura \\
\hline Implementar da coleta seletiva de lixo & Prefeitura \\
\hline Criar estabelecimentos de reciclagem & $\begin{array}{l}\text { Prefeitura e } \\
\text { Comunidades }\end{array}$ \\
\hline Separar o lixo orgânico doméstico e fazer adubo para ser utilizado em hortas & Comunidades \\
\hline Separar os lixos recicláveis para vender & Comunidades \\
\hline $\begin{array}{l}\text { Fiscalizar e aplicar de punições, como a prestação de serviços, para pessoas } \\
\text { que jogassem lixo no chão }\end{array}$ & Prefeitura \\
\hline Colocar grades nas margens dos rios para a população não jogar lixo & Prefeitura \\
\hline Substituir as tampas quebradas dos bueiros para evitar acidentes & Prefeitura \\
\hline $\begin{array}{l}\text { Promover manifestações para exigir do poder público a solução dos } \\
\text { problemas socioambientais }\end{array}$ & Comunidades locais \\
\hline $\begin{array}{l}\text { Realizar abaixo-assinado para reivindicar da prefeitura a solução dos } \\
\text { diferentes problemas socioambientais }\end{array}$ & Comunidades locais \\
\hline $\begin{array}{l}\text { Elaborar campanhas de conscientização da população a respeito dos } \\
\text { problemas socioambientais }\end{array}$ & $\begin{array}{l}\text { Sociedade e órgãos } \\
\text { públicos }\end{array}$ \\
\hline Realizar a pavimentação das ruas & Prefeitura \\
\hline Organizar mutirões para tapar os buracos nas ruas (medida temporária) & Comunidades \\
\hline Criar rede de esgoto nos locais onde não possui & $\begin{array}{l}\text { Governo estadual e } \\
\text { municipal }\end{array}$ \\
\hline Criar Estações de Tratamento de Esgoto & $\begin{array}{l}\text { Governo estadual } \\
\text { (CEDAE) }\end{array}$ \\
\hline Aumentar a segurança nos bairros através de um maior policiamento & Governo estadual \\
\hline $\begin{array}{l}\text { Implementar adaptações nas ruas para facilitar a mobilidade dos deficientes } \\
\text { físicos e visuais }\end{array}$ & Prefeitura \\
\hline $\begin{array}{l}\text { Voto consciente visando eleger candidatos que tenham uma preocupação } \\
\text { com os problemas socioambientais }\end{array}$ & \\
\hline
\end{tabular}

Fonte: Dados da pesquisa 
Percebe-se, através de uma análise geral das apresentações, debates e propostas, que as argumentações carecem de um embasamento mais sólido sobre as questões atinentes ao modus operandi do sistema dominante. No entanto, algumas colocações, mesmo que em pequena proporção, como as associadas ao voto consciente e à acessibilidade dos deficientes físicos e visuais sinalizam no sentido de uma percepção mais abrangente da questão socioambiental.

\section{Considerações Finais}

O presente estudo revelou que a percepção ambiental dos estudantes em relação ao meio ambiente do espaço de vivência está predominantemente associada aos problemas socioambientais. Notou-se que a ênfase dada aos problemas socioambientais está intimamente relacionada ao contexto atual do município de Itaboraí, caracterizado pela elevada intensidade de tais problemas. Esse quadro refletiu significativamente na percepção depreciativa que muitos estudantes demonstraram em relação ao seu espaço de vivência.

É importante ressaltar que, apesar da grande expressão dos problemas socioambientais nas representações, percebe-se uma valorização de elementos mais tradicionais relacionados a essa temática como os resíduos sólidos, a má conservação das ruas e a questão dos efluentes domésticos. Observa-se que os aspectos mais complexos que interligam política, economia e sociedade, que refletem a estrutura do sistema, ficaram ausentes nas representações, salvo raras exceções. Sendo assim, ficou visível a carência de uma percepção mais holística em relação aos problemas socioambientais.

A pesquisa mostrou também, a partir da atividade de confecção das representações geoespaciais coletivas dos problemas socioambientais, que 0 trabalho inserido no contexto de uma metodologia participativa, associado ao espaço cotidiano dos alunos, pode colaborar significativamente para a realização de uma educação mais autêntica e emancipadora, contribuindo para o processo de uma educação ambiental contextualizada e crítica. No entanto, apesar dos pontos positivos indicados pelo estudo, nota-se, através dessa prática pedagógica, que a concepção mais abrangente e complexa de meio ambiente ainda foi muito restrita diante da despolitização verificada nas representações geoespaciais. Porém, apesar das limitações verificadas de uma análise política e econômica mais engajada e sólida por parte do alunado, os resultados indicaram que estamos no caminho certo. Trata-se de um longo percurso a ser percorrido que não se encerra nessa pesquisa, mas que para alcançar os propósitos de contribuição para a transformação do status quo, deve ser contínuo e não esmorecer diante dos entraves estabelecidos pelo sistema dominante. 


\section{Referências}

BACCI, D. L. C.; SANTOS, V. M. N.; MARTINS, L. Aplicação do Mapeamento Socioambiental na Formação Inicial de Professores: uma Abordagem Metodológica Crítica e Participativa. Revista de Graduação USP - Grad+, v.2, n.1, p.05-12, mar. 2017. Disponível em: <http://www.revistas.usp.br/ gradmais/article/view/124420/126024>. Acesso em: 21 abr. 2019.

BACCI, D. L. C.; SANTOS, V. M. N. Mapeamento socioambiental como contribuição metodológica à formação de professores e aprendizagem social. Revista Geologia USP, Publicação Especial, São Paulo, v.6, p.19-28, ago. 2013.

BATISTA, N. L.; BECKER, E. L. S.; CASSOL, R. Os mapas mentais e a percepção ambiental dos alunos de ensino médio do município de Quevedos/RS. In: XI Encontro Nacional da ANPEGE, 2015, Presidente Prudente. Anais... Presidente Prudente - SP: ANPEGE, 2015. p. 3405-3416. Disponível em: <http://www.enanpege.ggf.br/2015/anais/arquivos/11/320.pdf>. Acesso em: 20 abr. 2019.

BRANCO, N. C. et al. Análise dos fatores motivadores de mortalidade das micro e pequenas empresas em Itaboraí/RJ a partir da implantação do Comperj (2006-2014). In: XII Congresso Nacional de excelência em gestão \& III Inovarse - Responsabilidade social aplicada, 2016, Rio de Janeiro. Anais... Rio de Janeiro: XII CNEG \& III INOVARSE, 2016.

CARVALHO, I. C. M.; STEIL, C. A. Percepção e ambiente: aportes para uma epistemologia ecológica. Revista Eletrônica do Mestrado em Educação Ambiental, volume especial, p. 59-79, março de 2013. Disponível em: $<$ https://periodicos.furg.br/remea/article/view/3443/2069>. Acesso em: $21 \mathrm{abr}$. 2019.

CARVALHO, I. C. M. Qual educação ambiental? Elementos para um debate sobre educação ambiental e extensão rural. Agroecologia e Desenvolvimento Rural Sustentável. Porto Alegre, v.2, no2, p. 43-51. abr-jun. de 2001.

CRUZ, A. A.; TEODORO, P. H. M. A cartografia social em ambientes escolares por uma educação ambiental crítica. Revista Espinhaço, v.5, n.1, p.39-47, 2016.

DUBA, V. H. C. As contradições nas tramas do cotidiano programado: a degradação da vida e a banalização do espaço na cidade de Itaboraí - RJ. 2016. 152f. Dissertação (Mestrado em Geografia). Programa de PósGraduação em Geografia do Departamento de Geografia e Meio Ambiente da Pontifícia Universidade Católica do Rio de Janeiro, Rio de Janeiro, 2016.

HELBEL, M. R. M.; VESTENA, C. L. B. Fenomenologia: a percepção ambiental como objeto de construção à Educação Ambiental. Revista Brasileira de Educação Ambiental (RevBEA). São Paulo, v.12, n.2, p.67-78, 2017. 
KASHIWAGI, H. M. O processo de percepção e apropriação do espaço nas comunidades marginais urbanas: o caso da favela do Parolin em Curitiba - PR. 2004. 192f. Dissertação (Mestrado em Geografia). Setor de Ciências da Terra da Universidade Federal do Paraná, Curitiba - PR, 2004.

KOZEL, S.; GALVÃO, W. Representação e ensino de geografia: contribuições teórico-metodológicas. Ateliê Geográfico, Goiânia-GO, v. 2, n. 3, p.33-48, dez. 2008. Disponível em: <https://revistas.ufg.br/atelie/article/view/5333/4394>. Acesso em: 21 abr. 2019.

KOZEL, S. Representação e Ensino: aguçando o olhar geográfico para os aspectos didático-pedagógicos. In: SERPA, A. (org.). Espaços culturais: vivências, imaginações e representações. Salvador: EDUFBA, p. 71 - 88, 2008.

KOZEL, S. Mapas Mentais - uma forma de linguagem: perspectivas metodológicas. In: KOZEL, S.; SILVA, J. C.; GIL FILHO, S. F. (Orgs.). Da percepção e cognição a representação: reconstruções teóricas da Geografia Cultural e Humanista. São Paulo: Terceira Margem, 2007.

LAYRARGUES, P. P.; LIMA, G. F. C. Mapeando as macro-tendências políticopedagógicas da Educação Ambiental contemporânea no Brasil. In: VI Encontro Pesquisa em Educação Ambiental, 2011, Ribeirão Preto. Anais... Ribeirão Preto: EPEA, p. 1-15, 2011 ..

LEFF, E. Discursos sustentáveis. São Paulo: Cortez, 2010.

MARIN, A. A. Pesquisa em educação ambiental e percepção ambiental. Pesquisa em Educação Ambiental, vol.3, n.1, p. 203-222, 2008.

MARQUES, A. L. B. A. A relevância dos mapas mentais e do Google Earth para a cartografia escolar: um estudo com graduandos de pedagogia. 2012. 104f. Dissertação (Mestrado em Educação). Programa de Pós-Graduação em Educação Brasileira, Centro de Educação da Universidade Federal de Alagoas, Maceió - AL, 2012.

MONIZ, M. A. Condições ambientais e riscos à saúde do contexto de construção do Complexo Petroquímico do Rio de Janeiro: um estudo de percepção dos atores sociais locais. 2016. 186f. Tese (Doutorado em Ciências). Programa de Pós-graduação em Saúde Pública e Meio Ambiente da Escola Nacional de Saúde Pública Sergio Arouca da Fundação Oswaldo Cruz, Rio de Janeiro, 2016.

OBRAC - Olimpíada Brasileira de Cartografia. Guia para realização da Etapa II - Fase 3, 2017. Disponível em: <http://www.olimpiadadecartografia.uff.br/ images/imagens/Guia Google My Maps e GPS.pdf>. Acesso em: 17 jun. 2018.

SATO, M. Debatendo os desafios da educação ambiental. Revista Eletrônica do Mestrado em Educação Ambiental, Rio Grande, v.1, p. R-14-R-33, 2001.

SEEMANN, J. Mapas e Percepção ambiental: do mental ao material e viceversa. OLAM: Ciência e Tecnologia, Rio Claro, n. 1, v. 3, p. 200 - 223, 2003. 
SOUSA, L. F. Espaços dialógicos dos barqueiros na Amazônia: uma relação humanista com o rio. 2012. 272f. Tese (Doutorado em Geografia). Universidade Federal do Paraná, Curitiba - PR, 2012.

SOUZA, C. J. O.; PEREIRA, M. B. Cartografia escolar na formação do professor de geografia e a prática com mapas mentais. Revista Brasileira de Educação em Geografia. Campinas (SP), v.7, n.13, p.248-276, jan./jun. 2017. Disponível

<http://www.revistaedugeo.com.br/ojs/index.php/revistaedugeo/article/view/513/ 255>. Acesso em: 20 abr. 2019.

TUAN, Y. Topofilia: um estudo da percepção, atitudes e valores do meio ambiente. São Paulo: Difel, 1980.

VIGOTSKI, L. S. A construção do pensamento e da linguagem. Tradução: Paulo Bezerra. São Paulo: Martins Fontes, 2001. 